\title{
The Prevalence of Non-alcoholic Fatty Liver Disease and Diabetes Mellitus in an Iranian Population
}

\author{
Behnam Rabiee ${ }^{1}$, Farzin Roozafzai ${ }^{1}$, Gholam Reza Hemasi ${ }^{1}$, Hossein Poustchi ${ }^{2}$, Hossein Keyvani ${ }^{3}$, \\ Mahmood Reza Khonsari ${ }^{1}$, Hossein Ajdarkosh ${ }^{1}$, Mansooreh Maadi ${ }^{1}$, \\ Fatemeh Sima Saeedian ${ }^{1}$, Farhad Zamani ${ }^{1, *}$
}

1. Gastrointestinal and Liver Disease Research Center, Firoozgar Hospital, Iran University of Medical Sciences, Tehran, Iran

2. Liver and Pancreatobiliary Diseases Research Center, Digestive Diseases Research Institute, Shariati Hospital, Tehran University of Medical Sciences, Tehran, Iran

3. Department of Virology, Tehran University of Medical Sciences, Tehran, Iran

\section{* Corresponding Author:}

Farhad Zamani, MD

Professor of Medicine, Department of Gastroenterology, Gastrointestinal and Liver Disease Research Center, Iran University of Medical Sciences, Firoozgar Hospital, Tehran, Iran. Tel: + 982188940489 fax: +982182141201 Email: zamani.farhad@gmail.com

Received: 26 Nov. 2016

Accepted: 28 Feb. 2017

\section{ABSTRACT}

\section{BACKGROUND}

Type II diabetes mellitus (T2DM) and non-alcoholic fatty liver disease (NAFLD) are important causes of morbidity and mortality worldwide. We aimed to estimate the prevalence of DM in the context of NAFLD

\section{METHODS}

In this cross-sectional study, we studied 5052 participants, aged 18 years and older, of a baseline population-based cohort in northern Iran $(\mathrm{N}=6143)$. The prevalence of DM was estimated in individuals with and without NAFLD. The association between NAFLD and T2DM was evaluated using logistic regression with the adjustment of confounding effects of age, sex, body mass index, lipid profiles, and fasting insulin.

\section{RESULTS}

In men, the prevalence $(95 \%$ confidence interval) of T2DM was $5.34 \%(4.35 \%-6.34 \%)$ and $15.06 \%(13.12 \%-17.00 \%)$ in individuals without and with NAFLD, respectively $(\mathrm{p}<0.001)$. In women without NAFLD, the prevalence was $8.27 \%(6.83 \%-9.71 \%)$ while in the presence of NAFLD, the prevalence was $27.21 \%(24.59 \%-29.83 \%),(\mathrm{p}<0.001)$. In univariate analysis, the chance of having T2DM was 3.700 (3.130-4.380) times more in patients with NAFLD compared with subjects without NAFLD $(\mathrm{p}<0.001)$. This chance was reduced (Odds Ratio $=1.976,95 \%$ CI: 1.593-2.451, $\mathrm{p}<0.001$ ) after removing the effects of other variables.

\section{CONCLUSION}

The prevalence of T2DM is increased in the context of NAFLD. This condition may be considered as an independent predictor of T2DM.

\section{KEYWORDS:}

Non-alcoholic fatty liver disease, Diabetes mellitus, Non-communicable disease, Prevalence, Iran.

Please cite this paper as:

Rabiee B, Roozafzai F, Hemasi GR, Poustchi H, Keyvani H, Khonsari MR, Ajdarkosh H, Maadi M, Sima Saeedian F, Zamani F. The Prevalence of Non-alcoholic Fatty Liver Disease and Diabetes Mellitus in an Iranian Population. Middle East J Dig Dis 2017;9:86-93. DOI: $10.15171 /$ mejdd.2017.56.

\section{INTRODUCTION}

Non-alcoholic fatty liver disease (NAFLD) is defined by cytoplasmic accumulation of fat in hepatocytes when the other causes of steatosis, such as excessive alcohol consumption, drugs, hepatitis $\mathrm{C}$ and $\mathrm{B}$ or genetic disorders are ruled out. ${ }^{1}$ The prevalence of NAFLD in general population of USA was estimated to be $27-34 \% .{ }^{2}$ The prevalence of NAFLD was $60-70 \%$ in American patients with diabetes and $42.6 \%$ and $69.5 \%$ in European patients with diabetes. ${ }^{3,4}$ Based on one meta-analysis, the prevalence of diabetes mellitus (DM) in adults $>40$ years was $24 \%$ and it was estimated that the prevalence 


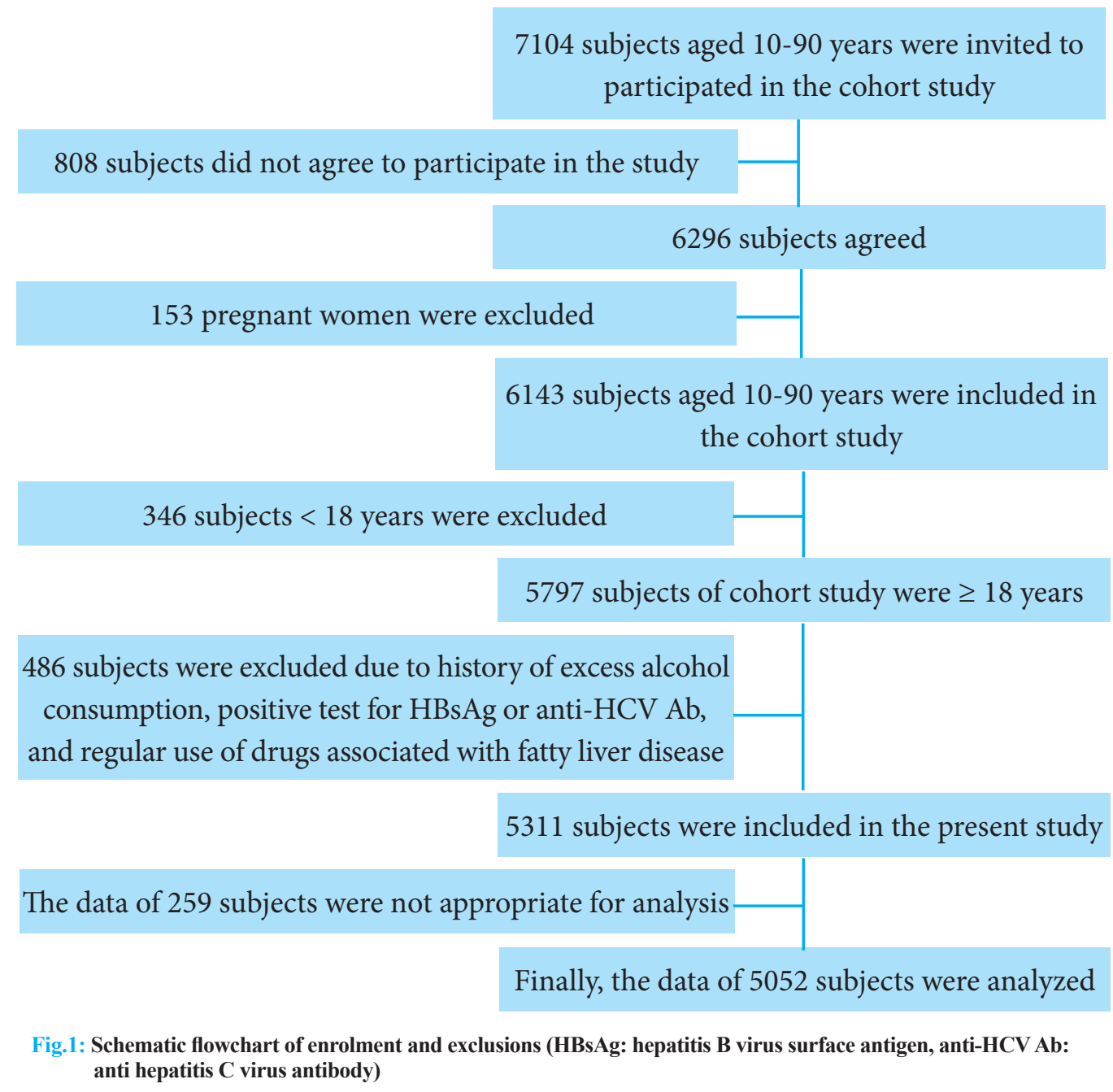

increases by $0.4 \%$ with one year increase in age after 20 years of age. ${ }^{5}$

NAFLD is considered as an emerging healthcare problem in Asian countries, ${ }^{6,7}$ with a prevalence of 15 $45 \%$, which is rising. ${ }^{7}$ The rising trend in the prevalence of obesity plays a critical role in the increasing trend of NAFLD prevalence..$^{8-11}$ According to the results of a meta-analysis in Iran, the prevalence of NAFLD was estimated $33.9 \% .^{12}$

On the other hand, the prevalence of type II diabetes mellitus (T2DM) and other metabolic disorders is dramatically increasing worldwide. ${ }^{13,14}$ Previous studies showed an increase in the incidence of NAFLD in case of T2DM..$^{15}$ Consequently, the increasing trend of NAFLD seems likely to continue in upcoming years due to the increasing prevalence of obesity and T2DM. ${ }^{15-17}$

Iran, as one of the low and middle income countries
(LMIC), is experiencing a high prevalence of obesity, which is predicted to keep rising in near future. ${ }^{18}$ Regarding the growing trend in the prevalence of both NAFLD and T2DM and the association between these two conditions, the present study was conducted to estimate and compare the prevalence of T2DM in individuals with and without NAFLD.

\section{MATERIALS AND METHODS}

In compliance with the principles of the Declaration of Helsinki, we studied 5052 of 6143 participants of a baseline cohort study of individuals aged 10 to 90 years. ${ }^{10,11,19-24}$ Our study subjects were 18 years and older among whom 2859 (56.6\%) were male and 2193 (43.4\%) were female. Enrolment process is shown in figure 1. Since September 2008, the baseline cohort study has been conducted in Amol, a populated city in northern 
Iran, by the Gastrointestinal and Liver Disease Research Centre (GILDRC) of Iran University of Medical Sciences (IUMS). Research Ethics Committee of IUMS approved the study protocol (reference number: IR.IUMS. rec.1394.19753) and all participants gave informed consent prior to their inclusion in the study. The written informed consent (in Persian) contained statements pertaining the rationale and benefits of participation in the cohort, the procedures such as blood sampling, the right to withdraw from the study at any time without giving reasons and without any penalty, and confidentiality of any disclosing data for each participant. The sampling frame was obtained from local health centers, where almost all the study participants had health records. Further explanation of sampling of cohort study is stated elsewhere. ${ }^{25,26}$

Data collection: Anthropometric measures (weight, height) and blood pressure were measured by trained healthcare staff. Height was measured at standing position with heels and buttocks pressed up against a wall. Blood pressure was measured using a fitted sphygmomanometer cuff after resting 5 minutes in a quiet room. We used Korotkoff sounds to determine systolic blood pressure (SBP) and diastolic blood pressure (DBP).

After 12-hour fasting, venous blood sample was taken from each participant to assess fasting blood sugar (FBS) and lipid profiles. All laboratory tests, including FBS, triglycerides (TGs), high-density lipoprotein (HDL), low-density lipoprotein (LDL), cholesterol, and aminotransferases were assessed enzymatically using BS200 Auto-analyzer (Mindray, Shenzhen, China). 10\% of the blood samples were re-evaluated by the Iranian National Reference Laboratory. The coefficients of variation ranged from $1.7 \%$ to $3.8 \%$ for all laboratory values.

NAFLD was defined by sonographic evidence of hepatic steatosis and ruling out other causes of acute or chronic hepatitis as well as secondary hepatic fat accumulation due to alcohol consumption, taking steatogenic medications, or hereditary disorders. A single expert radiologist did all ultrasound examinations using a 3-5 $\mathrm{MHz}$ transducer. Sagittal, longitudinal, lateral, and intercostal views of the liver parenchyma were obtained. Steatosis was confirmed when there was a markedly increased hepatic echogenicity. T2DM was defined by history of type II DM or taking anti-hyperglycemic drugs (oral agents, insulin), or a FBS $\geq 125 \mathrm{mg} / \mathrm{dL}$ without any history of type I DM.

Data analyses: We used descriptive statistics (frequency distribution, mean and standard deviation) to report the findings. Two group proportion test was used to compare the prevalence of T2DM in patients with and without NAFLD. The population was divided into 16 strata based on sex and age groups with 10-year intervals and comparisons were made in subgroups. Independent $t$ test was used to compare normally distributed variables, such as age, body mass index (BMI), SBP, DBP, mean arterial pressure (MAP), FBS, TG, total cholesterol, HDL, LDL, and aminotransferases. We used Mann-Whitney test to compare fasting insulin levels and insulin resistance indices (HOMA-IR) as they were not normally distributed in the two groups of patients (with and without NAFLD). We evaluated the associations between T2DM and age, sex, BMI, MAP, TG, LDL, HDL, fasting insulin, and NAFLD by univariate and multivariate logistic regression models and reported them in terms of odds ratio (OR) and confidence intervals (CI) and $\mathrm{P}$ values. The significance level for all analyses was considered 0.05 . The data were inferred statistically using IBM SPSS software version 22 (IBM Corp., Armonk, USA) and STATA software version 12 (StataCorp, Texas, USA).

\section{RESULTS}

Our study subjects were 18 years and older among whom 2860 (56.6\%) were male and 2192 (43.4\%) were female with a mean age ( \pm standard deviation) of 44.77 $( \pm 16.77)$ and $43.78( \pm 15.43)$ years, respectively. Table 1 shows the basic characteristics of the study population in "NAFLD" and "without NAFLD" groups. In both sexes, all characteristics were significantly higher in "NAFLD" group compared with "without NAFLD" group, except HDL that was significantly lower in "NAFLD" group. Table 2 demonstrates the prevalence of T2DM in people with and without NAFLD stratified by sex and age groups. There was a significantly higher prevalence of T2DM in NAFLD group in all subgroups except for women aged 65 years and older. We defined T2DM as the outcome variable to perform univariate and multivariate logistic regression analyses. According to univariate analysis, the relative risk of having $\mathrm{T} 2 \mathrm{DM}$ in patients 
Table 1: Basic characteristics of the study subjects with and without non-alcoholic fatty liver disease

\begin{tabular}{|c|c|c|c|c|}
\hline \multirow{2}{*}{ Sex } & \multirow{2}{*}{ Variables } & \multicolumn{2}{|c|}{ Mean \pm Standard Deviation } & \multirow{2}{*}{ Mean difference $(95 \% \mathrm{CI})$} \\
\hline & & Without NAFLD & With NAFLD & \\
\hline \multirow[t]{14}{*}{ Male } & Age (years) & $42.21 \pm 17.79$ & $48.58 \pm 14.29$ & $6.37(5.22-7.52)$ \\
\hline & $\mathrm{BMI}\left(\mathrm{Kg} / \mathrm{m}^{2}\right)$ & $24.33 \pm 3.66$ & $29.66 \pm 3.98$ & $5.32(5.06-5.59)$ \\
\hline & $\mathrm{SBP}(\mathrm{mmHg})$ & $114.27 \pm 14.84$ & $122.14 \pm 15.94$ & $7.87(6.81-8.94)$ \\
\hline & DBP (mmHg) & $73.74 \pm 12.19$ & $80.93 \pm 12.21$ & $7.19(6.33-8.04)$ \\
\hline & MAP (mmHg) & $87.25 \pm 12.19$ & $94.66 \pm 12.66$ & $7.41(6.55-8.28)$ \\
\hline & FBS (mg/dL) & $94.73 \pm 26.89$ & $104.42 \pm 32.99$ & $9.69(7.63-11.75)$ \\
\hline & $\mathrm{TG}(\mathrm{mg} / \mathrm{dL})$ & $123.90 \pm 78.40$ & $175.46 \pm 113.84$ & $51.56(44.75-58.38)$ \\
\hline & Total Cholesterol (mg/dL) & $171.13 \pm 40.70$ & $189.48 \pm 41.39$ & $18.35(15.48-21.21)$ \\
\hline & $\mathrm{HDL}(\mathrm{mg} / \mathrm{dL})$ & $45.46 \pm 11.41$ & $40.21 \pm 10.84$ & $-5.25(-6.05--4.45)$ \\
\hline & LDL (mg/dL) & $99.82 \pm 30.40$ & $112.16 \pm 30.30$ & $12.34(10.17-14.50)$ \\
\hline & Fasting insulin (mIU/L) & $7.40 \pm 5.37$ & $11.08 \pm 7.89$ & $3.68(3.23-4.13)$ \\
\hline & HOMA-IR & $1.74 \pm 1.39$ & $2.86 \pm 2.32$ & $1.12(0.99-1.25)$ \\
\hline & AST (IU/L) & $22.74 \pm 10.75$ & $25.84 \pm 14.86$ & $3.10(2.22-3.97)$ \\
\hline & ALT (IU/L) & $22.44 \pm 15.57$ & $32.46 \pm 21.95$ & $10.02(8.73-11.30)$ \\
\hline \multirow[t]{14}{*}{ Female } & Age (years) & $38.28 \pm 15.28$ & $50.72 \pm 12.54$ & $12.44(11.32-13.55)$ \\
\hline & BMI $\left(\mathrm{Kg} / \mathrm{m}^{2}\right)$ & $26.96 \pm 4.85$ & $33.07 \pm 4.73$ & $6.11(5.73-6.49)$ \\
\hline & $\mathrm{SBP}(\mathrm{mmHg})$ & $110.36 \pm 15.89$ & $121.82 \pm 17.91$ & $11.47(10.16-12.78)$ \\
\hline & DBP (mmHg) & $72.28 \pm 12.24$ & $80.27 \pm 12.68$ & $7.99(7.01-8.97)$ \\
\hline & MAP (mmHg) & $84.97 \pm 12.28$ & $94.11 \pm 13.51$ & $9.14(8.12-10.15)$ \\
\hline & FBS (mg/dL) & $95.29 \pm 31.17$ & $114.97 \pm 49.19$ & $19.68(16.52-22.84)$ \\
\hline & $\mathrm{TG}(\mathrm{mg} / \mathrm{dL})$ & $115.14 \pm 66.10$ & $171.83 \pm 114.92$ & $56.70(49.25-64.14)$ \\
\hline & Total Cholesterol (mg/dL) & $180.71 \pm 40.66$ & $200.51 \pm 43.81$ & $19.80(16.48-23.11)$ \\
\hline & $\mathrm{HDL}(\mathrm{mg} / \mathrm{dL})$ & $49.04 \pm 11.69$ & $43.01 \pm 11.72$ & $-6.03(-6.98--5.08)$ \\
\hline & LDL (mg/dL) & $104.87 \pm 30.53$ & $116.56 \pm 31.74$ & $11.69(9.18-14.19)$ \\
\hline & Fasting insulin (mIU/L) & $9.42 \pm 6.50$ & $11.55 \pm 7.15$ & $2.13(1.59-2.66)$ \\
\hline & HOMA-IR & $2.22 \pm 1.73$ & $3.35 \pm 3.02$ & $1.12(0.93-1.31) \dagger$ \\
\hline & AST (IU/L) & $18.79 \pm 6.72$ & $21.47 \pm 12.35$ & $2.67(1.92-3.43)$ \\
\hline & ALT (IU/L) & $17.34 \pm 12.29$ & $22.42 \pm 15.51$ & $5.08(3.99-6.16)$ \\
\hline
\end{tabular}

ALT: alanine aminotransferase, AST: aspartate aminotransferase, BMI: body mass index, CI: confidence interval, DBP: diastolic blood pressure, FBS: fasting blood sugar, HDL: high-density lipoprotein, HOMA-IR: homeostatic model assessment-insulin resistance, LDL: low-density lipoprotein, MAP: mean arterial pressure, NAFLD: non-alcoholic fatty liver disease, SBP: systolic blood pressure, TG: triglycerides

Table 2: Prevalence of type 2 diabetes mellitus in subjects with and without non-alcoholic fatty liver disease according to sex and age groups

\begin{tabular}{|c|c|c|c|c|}
\hline \multirow{2}{*}{ Sex } & \multirow{2}{*}{ Age group (years) } & \multicolumn{2}{|c|}{ Percentage } & \multirow{2}{*}{ OR (95\%CI) } \\
\hline & & Without NAFLD & With NAFLD & \\
\hline \multirow[t]{4}{*}{ Male } & $18-39$ & 1.27 & 4.49 & $3.667(1.717-7.830)$ \\
\hline & $40-64$ & 6.67 & 15.59 & $2.590(1.832-3.662)$ \\
\hline & $\geq 65$ & 16.10 & 33.34 & $2.605(1.664-4.078)$ \\
\hline & Total $\geq 18$ & 5.34 & 15.06 & $3.140(2.450-4.024)$ \\
\hline \multirow[t]{4}{*}{ Female } & $18-39$ & 1.58 & 9.95 & $6.887(3.387-14.00)$ \\
\hline & $40-64$ & 16.39 & 30.36 & $2.224(1.669-2.963)$ \\
\hline & $\geq 65$ & 24.49 & 35.81 & $1.720(0.973-3.042)$ \\
\hline & Total $\geq 18$ & 8.27 & 27.21 & $4.147(3.290-5.227)$ \\
\hline
\end{tabular}

NAFLD: non-alcoholic fatty liver disease, OR: odd ratio 
Table 3: Results of univariate and multivariate logistic regression analyses with type 2 diabetes mellitus as outcome variable

\begin{tabular}{|c|c|c|c|c|}
\hline Analysis & Variables & $\beta$ coefficient (SE) & Wald test & Odd ratio $(95 \% \mathrm{CI})$ \\
\hline \multirow{9}{*}{ 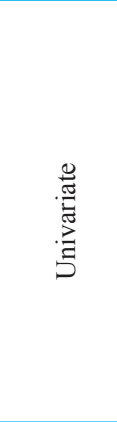 } & Age & $0.058(0.003)$ & 423.51 & $1.059(1.053-1.065)$ \\
\hline & Sex & $0.673(0.081)$ & 69.64 & $1.960(1.674-2.296)$ \\
\hline & BMI & $0.081(0.007)$ & 124.13 & $1.084(1.069-1.100)$ \\
\hline & MAP & $0.032(0.003)$ & 127.70 & $1.033(1.027-1.039)$ \\
\hline & $\mathrm{TG}$ & $0.004(0.0003)$ & 105.31 & $1.004(1.003-1.005)$ \\
\hline & LDL & $0.007(0.001)$ & 33.96 & $1.007(1.005-1.010)$ \\
\hline & HDL & $-0.026(0.004)$ & 49.69 & $0.974(0.967-0.981)$ \\
\hline & Fasting Insulin & $0.018(0.005)$ & 12.75 & $1.019(1.008-1.029)$ \\
\hline & NAFLD & $1.308(0.086)$ & 232.38 & $3.700(3.130-4.380)$ \\
\hline \multirow{9}{*}{ 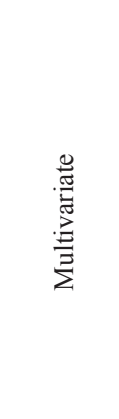 } & Age & $0.061(0.003)$ & 303.351 & $1.063(1.055-1.070)$ \\
\hline & Sex & $0.846(0.099)$ & 72.287 & $2.329(1.917-2.831)$ \\
\hline & BMI & $-0.008(0.011)$ & 0.528 & $0.992(0.970-1.014)$ \\
\hline & MAP & $0.005(0.003)$ & 2.017 & $1.005(0.998-1.012)$ \\
\hline & TG & $0.003(0.0005)$ & 39.174 & $1.003(1.002-1.004)$ \\
\hline & LDL & $-0.002(0.001)$ & 1.744 & $0.998(0.995-1.001)$ \\
\hline & HDL & $-0.014(0.004)$ & 10.660 & $0.986(0.978-0.995)$ \\
\hline & Fasting Insulin & $0.015(0.007)$ & 4.847 & $1.015(1.002-1.029)$ \\
\hline & NAFLD & $0.681(0.110)$ & 38.411 & $1.976(1.593-2.451)$ \\
\hline
\end{tabular}

BMI: body mass index, CI: confidence interval, HDL: high-density lipoprotein, LDL: low-density lipoprotein, MAP: mean arterial pressure, NAFLD: non-alcoholic fatty liver disease, SE: standard error, TG: triglycerides.

with NAFLD, compared with subjects without NAFLD, was 3.700 (95\% CI: 3.130-4.380, p<0.001). After adjustment of confounding variables including age, sex, BMI, TG, LDL, HDL, and insulin, the risk was reduced to 1.976 (95\% CI: $1.593-2.451, \mathrm{p}<0.001)$. Among variables entered into multivariate model, age $(p<0.001)$, sex $(\mathrm{p}<0.001)$, TG $(\mathrm{p}<0.001)$, HDL $(\mathrm{p}=0.001)$, and fasting insulin ( $\mathrm{p}=0.028$ ) had a significant association with T2DM in addition to NAFLD $(p<0.001)$. More details are represented in table 3 .

\section{DISCUSSION}

Our results showed that in both men and women, the prevalence of T2DM dramatically increases in patients with NAFLD compared with individuals without NAFLD. Based on our results, $15 \%$ of men and $27 \%$ of women aged 18 years and older with NAFLD had comorbid T2DM, while the prevalence was 5\% and $8 \%$ in men and women without NAFLD, respectively. Similar results were reproduced after the data were analyzed according to age groups. In an agreement with our findings, Ortiz-Lopez and colleagues reported a dramatically higher prevalence of pre-diabetes and T2DM in patients with NAFLD compared with ones without NAFLD. ${ }^{27}$ Prior population-based studies showed an 11-18\% prevalence of T2DM in patients with NAFLD. ${ }^{28,29}$ NAFLD was suggested as a better predictor for T2DM than BMI in a Chinese population. ${ }^{30}$ Another observation estimated that $66 \%$ of patients with diabetes would have NAFLD and significant hepatic fibrosis. ${ }^{31}$

Patients with NAFLD have a 3.700 (95\% CI: 3.1304.380) times more chance of having T2DM compared with subjects without NAFLD, we observed. A previous study calculated a relative risk of 4.492 (95\% CI: 3.640-5.542) for T2DM in patients with NAFLD compared with individuals without NAFLD.30 We found a significant association between NAFLD and T2DM after adjusting confounding effects of other variables, such as BMI, MAP, lipid profiles, fasting insulin, age, and sex (Odds Ratio=1.976; 95\% CI: 1.593-2.451, $\mathrm{P}<0.001$ ). In line with our results, $\mathrm{Li}$ and co-workers declared NAFLD as a risk factor for T2DM independent of obesity or overweight. ${ }^{30}$

As mentioned before, we evaluated the prevalence of T2DM in the patients with NAFLD in different age groups $(18-39,40-64$, over 64 years $)$ of both sexes. The 
prevalence of T2DM was significantly higher in patients with NAFLD than patients without this condition in all age groups and the difference was markedly greater in 40-64 years age group of both sexes and in men over 64 years. Note worthily, NAFLD is thought to be a hepatic manifestation of metabolic syndrome (MetS) and a strong risk factor of MetS and also an important predictor of development of T2DM. ${ }^{32-34}$

The excessive liver fat is associated with hepatic, adipose tissue, and muscle insulin resistance. Consequently, individuals harboring fatty liver, either with or without obesity, may be predisposed to develop MetS and T2DM. On the other hand, T2DM may be considered as a risk factor for developing moderate and severe fibrosis and also a predisposing risk factor for the development of hepatocellular carcinoma in the context of NAFLD. ${ }^{32-36} \mathrm{~A}$ reciprocal relationship is conceivable between NAFLD and metabolic disorders such as T2DM. ${ }^{32-34}$ Furthermore, NAFLD can lead to hepatocellular carcinoma even without any evidence of underlying cirrhosis. ${ }^{37,38}$ The results show an integrated approach for prevention and control of these two conditions can lead to proper management of non-communicable diseases (NCD) at the community level. Regarding its high prevalence in population, NAFLD may have a high population attributable fraction (PAF) for associated conditions including T2DM, MetS, cardiovascular diseases (CVD), and malignancies. In the other words, the incidence of population diseases, including conditions mentioned above, may decrease if exposure to NAFLD is reduced. On the other hand, almost all conditions mentioned above have common underlying causes and risk factors. As a result, an integrating and comprehensive community-based intervention should be recommended to control the related modifiable risk factors, particularly in LMICs where the high incidence of NCDs, such as NAFLD, T2DM, CVD, and malignancies, is considered an emerging challenge of globalization in primary healthcare.

In our study, NAFLD was defined by radiological evidence investigated by a single operator, while liver biopsy is the gold standard for diagnosis of NAFLD. However, biopsy is not an optimal tool for diagnosis of NAFLD in the population-based studies due to its complications and its high false positive rate. ${ }^{39,40}$ These limitations in addition to methodological ones, emanated from the de- scriptive design, affect the study psychometrics.

In conclusion, the prevalence of T2DM dramatically increases in the context of NAFLD. This condition may be considered as an independent predictor of T2DM. An integrated population-based intervention may reduce the burden of many NCDs, such as NAFLD and T2DM.

\section{ACKNOWLEDGMENTS}

This study was financially supported by Gastrointestinal and Liver Diseases Research Center (GILDRC) of Iran University of Medical Sciences (IUMS).

Source of funding: This study was financially supported by Gastrointestinal and Liver Diseases Research Center (GILDRC) of Iran University of Medical Sciences (IUMS).

Authors' contributions: FZ designed the concept. All authors collaborated in data acquisition. FZ and HP provided statistical advice on study design and data analysis. FR and BR analyzed and interpreted the data. FR drafted the manuscript. All authors critically reviewed the manuscript. All authors read and approved the final manuscript. FZ is the guarantor and takes responsibility for the paper as a whole.

\section{CONFLICT OF INTEREST}

The authors declare no conflict of interest related to this work.

\section{REFERENCES}

1. Angulo P, Lindor KD. Non-alcoholic fatty liver disease. $J$ Gastroenterol Hepatol 2002;17 Suppl:S186-90. doi: 10.1046/j.1440-1746.17.s1.10.x.

2. Vernon G, Baranova A, Younossi ZM. Systematic review: the epidemiology and natural history of non-alcoholic fatty liver disease and non-alcoholic steatohepatitis in adults. Aliment Pharmacol Ther 2011;34:274-85. doi: 10.1111/j.1365-2036.2011.04724.x.

3. Chalasani N, Younossi Z, Lavine JE, Diehl AM, Brunt EM, Cusi K, et al. The diagnosis and management of non-alcoholic fatty liver disease: practice Guideline by the American Association for the Study of Liver Diseases, American College of Gastroenterology, and the Am Gastroenterol Assoc Hepatol 2012;55:2005-23. doi: 10.1002/hep.25762.

4. Blachier M, Leleu H, Peck-Radosavljevic M, Valla DC, Roudot-Thoraval F. The burden of liver disease in Europe: a review of available epidemiological data. $J$ Hepatol 
2013;58:593-608. doi: 10.1016/j.jhep.2012.12.005.

5. Haghdoost A, Rezazadeh-Kermani M, Sadghirad B, Baradaran H. Prevalence of type 2 diabetes in the Islamic Republic of Iran: systematic review and meta-analysis. East Mediterr Health J 2009;15:591-9.

6. Sanyal AJ. NASH: A global health problem. Hepatol Res 2011;41:670-4. doi: 10.1111/j.1872-034X.2011.00824.x.

7. Farrell GC, Wong VW, Chitturi S. NAFLD in Asia--as common and important as in the West. Nat Rev Gastroenterol Hepatol 2013;10:307-18. doi: 10.1038/nrgastro.2013.34.

8. Finucane MM, Stevens GA, Cowan MJ, Danaei G, Lin JK, Paciorek CJ, et al. National, regional, and global trends in body-mass index since 1980: systematic analysis of health examination surveys and epidemiological studies with 960 country-years and 9.1 million participants. Lancet 2011;377:557-67. doi: 10.1016/S0140-6736(10)62037-5.

9. Deurenberg P, Yap M, van Staveren WA. Body mass index and percent body fat: a meta analysis among different ethnic groups. Int J Obes Relat Metab Disord 1998;22:116471.

10. Motamed N, Miresmail SJH, Rabiee B, Keyvani H, Farahani B, Maadi M, et al. Optimal cutoff points for HOMA-IR and QUICKI in the diagnosis of metabolic syndrome and non-alcoholic fatty liver disease: A population based study. J Diabetes Complications 2016;30:269-74. doi: 10.1016/j. jdiacomp.2015.11.019.

11. Motamed N, Sohrabi M, Ajdarkosh H, Hemmasi G, Maadi M, Sayeedian FS, et al. Fatty liver index vs waist circumference for predicting non-alcoholic fatty liver disease. World J Gastroenterol 2016;22:3023. doi: 10.3748/WJG. v22.i10.3023.

12. Moghaddasifar I, Lankarani K, Moosazadeh M, Afshari M, Ghaemi A, Aliramezany M, et al. Prevalence of Nonalcoholic Fatty Liver Disease and Its Related Factors in Iran. Int J Organ Transplant Med 2016;7:149-60.

13. International Diabetes F. Five questions on the IDF Diabetes Atlas. Diabetes Res Clin Pract 2013;102:147-8. doi: 10.1016/j.diabres.2013.10.013.

14. Hossain P, Kawar B, El Nahas M. Obesity and diabetes in the developing world--a growing challenge. New Engl $J$ Med 2007;356:213-5. doi: 10.1056/NEJMp068177.

15. Gupte P, Amarapurkar D, Agal S, Baijal R, Kulshrestha P, Pramanik S, et al. Non-alcoholic steatohepatitis in type 2 diabetes mellitus. J Gastroenterol Hepatol 2004;19:854-8. doi: 10.1111/j.1440-1746.2004.03312.x.

16. Bjornsson E, Angulo P. Non-alcoholic fatty liver disease. Scand J Gastroenterol 2007;42:1023-30. doi. org/10.1080/00365520701514529.

17. Flegal KM, Carroll MD, Ogden CL, Johnson CL. Prevalence and trends in obesity among US adults, 1999-2000. JAMA 2002;288:1723-7. doi:10.1001/jama.288.14.1723.

18. Rahmani A, Sayehmiri K, Asadollahi K, Sarokhani D, Islami F, Sarokhani M. Investigation of the Prevalence of Obesity in Iran: a Systematic Review and MetaAnalysis Study. Acta Med Iran 2015;53:596-607. doi. org/10.1155/2013/373857.

19. Motamed N, Rabiee B, Perumal D, Poustchi H, Miresmail SJH, Farahani B, et al. Comparison of cardiovascular risk assessment tools and their guidelines in evaluation of 10-year CVD risk and preventive recommendations: A population based study. Int J Cardiol 2017;228:52-57. doi: 10.1016/j.ijcard.2016.11.048.

20. Rabiee B, Motamed N, Hosseini V, Hemasi GR, Maadi M, Zamani F. Gastro esophageal reflux disease (GERD) prevalence and related risk factors in north of Iran. Esophagus 2016:1-7. doi: 10.1007/s10388-016-0536-6.

21. Motamed N, Rabiee B, Hemasi GR, Ajdarkosh H, Khonsari MR, Maadi M, et al. Body Roundness Index and Waist-to-Height Ratio are Strongly Associated With NonAlcoholic Fatty Liver Disease: A Population-Based Study. Hepat Mon 2016;16. doi: 10.5812/hepatmon.39575.

22. Motamed N, Rabiee B, Keyvani H, Hemasi GR, Khonsari M, Saeedian FS, et al. The Best Obesity Indices to Discriminate Type 2 Diabetes Mellitus. Metab Syndr Relat Disord 2016;14:249-53. doi: 10.1089/met.2015.0133.

23. Motamed N, Rabiee B, Poustchi H, Dehestani B, Hemasi GR, Khonsari MR, et al. Non-alcoholic fatty liver disease (NAFLD) and 10-year risk of cardiovascular diseases. Clin Res Hepatol Gastroenterol 2017;41:31-38. doi: 10.1016/j. clinre.2016.07.005.

24. Motamed N, Zamani F, Rabiee B, Saeedian F, Maadi M, Akhavan-Niaki H, et al. The Best Obesity Indices to Use in a Single Factor Model Indicating Metabolic Syndrome: a Population Based Study. Arch Iran Med 2016;19:110-5. doi:10.1089/met.2015.0133.

25. Zamani F, Sohrabi M, Alipour A, Motamed N, Saeedian FS, Pirzad R, et al. Prevalence and risk factors of cholelithiasis in Amol city, northern Iran: a population based study. Arch Iran Med 2014;17:750-4. doi: 0141711/AIM.006.

26. Ostovaneh M, Zamani F, Sharafkhah M, Ansari-Moghaddam A, Akhavan KN, Saeedian F, et al. Prevalence of metabolic syndrome in Amol and Zahedan, Iran: a population based study. Arch Iran Med 2014;17:477-82. doi: 0141707/AIM.006.

27. Ortiz-Lopez C, Lomonaco R, Orsak B, Finch J, Chang Z, Kochunov VG, et al. Prevalence of prediabetes and diabetes and metabolic profile of patients with nonalcoholic fatty liver disease (NAFLD). Diabetes Care 2012;35:8738. doi.org/10.2337/dc11-1849.

28. Browning JD, Szczepaniak LS, Dobbins R, Nuremberg P, Horton JD, Cohen JC, et al. Prevalence of hepatic steatosis in an urban population in the United States: impact of ethnicity. Hepatology 2004;40:1387-95. doi: 10.1002/ hep.20466.

29. Wong VW, Chu WC, Wong GL, Chan RS, Chim AM, Ong A, et al. Prevalence of non-alcoholic fatty liver disease and advanced fibrosis in Hong Kong Chinese: a population study using proton-magnetic resonance spectroscopy and transient elastography. Gut 2012;61:409-15. doi. 
org/10.1136/gutjnl-2011-300342.

30. Li WD, Fu KF, Li GM, Lian YS, Ren AM, Chen YJ, et al. Comparison of effects of obesity and non-alcoholic fatty liver disease on incidence of type 2 diabetes mellitus. World J Gastroenterol 2015;21:9607-13. doi: 10.3748/ WJG.v21.i32.9607.

31. Sobhonslidsuk A, Pulsombat A, Kaewdoung P, Petraksa S. Non-alcoholic fatty liver disease (NAFLD) and significant hepatic fibrosis defined by non-invasive assessment in patients with type 2 diabetes. Asian Pac J Cancer Prev 2015;16:1789-94. doi: 10.7314/APJCP.2015.16.5.1789.

32. Kotronen A, Westerbacka J, Bergholm R, Pietilainen KH, Yki-Jarvinen H. Liver fat in the metabolic syndrome. J Clin Endocrinol Metab 2007;92:3490-7. doi: 10.1210/jc.20070482 .

33. Bugianesi E, McCullough AJ, Marchesini G. Insulin resistance: a metabolic pathway to chronic liver disease. Hepatology 2005;42:987-1000. doi: 10.1002/hep.20920.

34. Perseghin G. Viewpoints on the way to a consensus session: where does insulin resistance start? The liver. Diabetes Care 2009;32 Suppl 2:S164-7. doi:10.2337/dc09-S303.

35. Jacqueminet S, Lebray P, Morra R, Munteanu M, Devers L, Messous D, et al. Screening for liver fibrosis by using a noninvasive biomarker in patients with diabetes. Clin Gastroenterol Hepatol 2008;6:828-31. doi: 10.1016/j. cgh.2008.03.005.

36. Williamson RM, Price JF, Hayes PC, Glancy S, Frier BM, Johnston GI, et al. Prevalence and markers of advanced liver disease in type 2 diabetes. QJM 2012;105:425-32. doi: 10.1093/qjmed/hor233.

37. Stickel F, Hellerbrand C. Non-alcoholic fatty liver disease as a risk factor for hepatocellular carcinoma: mechanisms and implications. Gut 2010;59:1303-7. doi:10.1136/ gut.2009.199661.

38. Sanyal A, Poklepovic A, Moyneur E, Barghout V. Population-based risk factors and resource utilization for HCC: US perspective. Curr Med Res Opin 2010;26:2183-91. doi: 10.1185/03007995.2010.506375.

39. Ratziu V, Charlotte F, Heurtier A, Gombert S, Giral P, Bruckert E, et al. Sampling variability of liver biopsy in nonalcoholic fatty liver disease. Gastroenterology 2005;128:1898-906. doi: 10.1053/j.gastro.2005.03.084.

40. Rockey DC, Caldwell SH, Goodman ZD, Nelson RC, Smith AD, American Association for the Study of Liver D. Liver biopsy. Hepatology 2009;49:1017-44. doi: 10.1002/ hep. 22742 . 